\title{
Suppression of Akt1 expression by small interference RNA inhibits SGC7901 cell growth in vitro and in vivo
}

\author{
XIAO-WEI CUI ${ }^{1}$, FENG-JUAN ZHAO ${ }^{1}$, JIAN LIU $^{1}$, XIAO-MEI SONG ${ }^{1}$, PENG XU $^{2}$, XUAN ZHOU $^{2}$, \\ JIE ZHANG ${ }^{1}$, TAO WANG ${ }^{1}$, CHUN-SHENG KANG ${ }^{2}$ and QING-YU ZHANG ${ }^{1}$ \\ ${ }^{1}$ Department of Gastroenteropathy, Tianjin Medical University General Hospital; ${ }^{2}$ Department of Neurosurgery, \\ Tianjin Medical University General Hospital and Laboratory of Neuro-Oncology, \\ Tianjin Neurological Institute, Tianjin 300052, P.R. China
}

Received May 19, 2009; Accepted August 5, 2009

DOI: $10.3892 /$ or_00000569

\begin{abstract}
The Akt/PKB kinase family, including Akt1, 2 and 3 , plays critical roles in regulating cell growth, proliferation, survival, metabolic and many other cellular activities. Recent evidence indicates that $\mathrm{PKB} / \mathrm{Akt}$ is frequently constitutively active in many types of human cancer including gastric cancer. In the present study, we applied immunohistochemistry to tissue microarray to detect the expression of Akt1, followed by Akt1 small interference RNA (siRNA) to examine knock down of the Akt1 gene on the growth inhibition of human gastric cancer SGC7901 cells. Our results indicate that the expression of Akt1 was significantly increased in gastric cancer compared to normal gastric tissue and adjacent non-cancer tissue. The in vitro study shows that cell growth was significantly inhibited and G0/G1 arrest was observed in siRNAAkt1-treated group. In vivo, the size of tumors was significantly smaller in SGC7901 subcutaneous mice model treated with siRNA-Akt1 than those treated with siRNA-nonsense and PBS. Our studies demonstrated siRNA-Akt1 can inhibit Akt1 expression, exerted growth inhibition effect on SGC7901 cells in vitro and in vivo. Suppression of Akt1 expression by siRNA could be a new strategy in gastric cancer treatment.
\end{abstract}

\section{Introduction}

Over the past five decades, the mortality associated with gastric cancer has decreased markedly in the world $(1,2)$. However,

Correspondence to: Dr Qing-Yu Zhang, Department of Gastroenteropathy, Tianjin Medical University General Hospital, 154 An-Shan Road, Heping District, Tianjin 300052, P.R. China E-mail: zhangqy@tijmu.edu.cn

Dr Chun-Sheng Kang, Department of Neurosurgery, Tianjin Medical University General Hospital and Laboratory of Neuro-Oncology, Tianjin Neurological Institute, 154 An-Shan Road, Heping District, Tianjin 300052, P.R. China

E-mail: kang97061@yahoo.com

Key words: Akt1, small interference RNA, gastric cancer, cell proliferation in some individual cases, five-year survival rate after diagnosis of gastric cancer is still low $(3,4)$. Gastric cancer remains the second leading cause of cancer death worldwide (1). In the USA alone, gastric cancer accounts for $2 \%$ of all cancer deaths (1).

It is believed that various human cancers, including gastric carcinoma, develop through the accumulation of several genetic alterations such as the inactivation of tumor suppressor genes or the activation of oncogenes. Protein kinase B or Akt (PKB/Akt) is a serine/threonine kinase, it appears that Akt/ PKB lies in the crossroads of multiple cellular signaling pathways and acts as a transducer of many functions initiated by growth factor receptors, and regulates various cell processes such as cell survival, cell cycle, metabolism, protein synthesis, apoptosis as well as transcriptional regulation $(5,6)$.

Recent evidence indicates that $\mathrm{PKB} / \mathrm{Akt}$ is frequently constitutively active in many types of human cancer, including gastric cancer $(7,8)$. Constitutive $\mathrm{PKB} /$ Akt activation can occur due to amplification of PKB/Akt genes or as a result of mutations in components of the signaling pathway that activates $\mathrm{PKB} / \mathrm{Akt}$.

Although Akt overexpression has been detected in certain tumor types such as colon, ovarian and pancreatic carcinoma $(9,10)$, the role of Akt in tumor biology has not been well studied in other tumor systems. Most of the studies are centered on the functional importance of overall Akt activity in various cell types without sufficient consideration of the roles of individual Akt isoforms, despite the obvious significance for specific therapeutic targeting. In the current study, we constructed the siRNA-Akt1 and transfected them into the gastric cancer cell line SGC7901 to investigate the influence of down-regulation of Akt1 on tumor biology.

\section{Materials and methods}

Tissue microarray/immunohistochemistry. We constructed a tissue array consisting of 100 representative 1-mm cores from formalin-fixed, paraffin-embedded tissue blocks from each of 45 gastric adenocarcinoma (25 samples of poorly differentiated adenocarcinoma, 10 samples of moderately differentiated adenocarcinoma, 10 samples of well-differentiated adenocarcinoma), and the gastric mucosa surrounding carcinomas 
Table I. siRNA sequences targeting Akt1.

\begin{tabular}{lc}
\hline Name & \multicolumn{1}{c}{ Sequence } \\
\hline Nonsense siRNA & 5'-AATTCTCCGAACGTGTCACGTTT-3' \\
Akt1 siRNA & \\
Sense & 5'-GGAGAUCAUGCAGCAUCGC-3' \\
Anti-sense & 5'-GCGAUGCUGCAUGAUCUCC-3' \\
\hline
\end{tabular}

as positive control, and 10 samples of normal gastric tissues as negative control. Immunohistochemistry steps were the same as described in the in vivo study.

siRNA constructs. Small interfering RNA specifically targeting Akt1 were constructed as described by Elbashir and colleagues (11), and chemically synthesized (Shanghai GenePharma Co., Ltd., China). The short RNA oligonucleotids used are listed in Table I.

Cell culture and transfection. Human gastric cancer SGC7901 cells were kindly provided by Dr Daiming Fan. Cells were cultured in Dulbecco's modified Eagle's medium (DMEM) supplemented with $10 \%$ heat-inactivated fetal calf serum, incubated in $5 \% \mathrm{CO}_{2}$ at $37^{\circ} \mathrm{C}$. For gene transfection, $2 \times 10^{5}$ cells per well were plated into six-well plates and grown overnight until they were $50-80 \%$ confluent. siRNA-Akt1 was transfected into SGC7901 cells by oligofectamine as instructed by the manufacturer.

Western blot analysis. After 24-48 h of transfection, cells were washed 3 times with ice-cold phosphate-buffered saline (PBS). Then the cells were lysed by RIPA (Solarbio Company, China) and PMSF protease inhibitor mixture. Homogenates were clarified by centrifugation at $12000 \mathrm{rpm}$ for $15 \mathrm{~min}$ at $4^{\circ} \mathrm{C}$ and protein concentrations were determined by Nanodrop ND1000 spectrophotometer (Gene Company, USA). The same amount of protein samples were applied onto SDS-PAGE at $60 \mathrm{~V}$ for $1 \mathrm{~h}$; separate proteins were transferred to PVDF membranes (Millipore, USA) at $80 \mathrm{~V}$ followed by blocking with $10 \%$ non-fat dry milk. The membranes were incubated with primary antibody against Akt1 (1:1000 dilution, Santa Cruz Biotechnology), followed by incubation with HRPconjugated secondary antibody (1:1000 dilution, Zhongshanjinqiao, China). The blots were then reacted with enhanced chemiluminescence Western blot detection system (Pierce, USA). After washing with stripping buffer, the membrane was re-probed with antibody against $\beta$-actin (1:500 dilution, Santa Cruz Biotechnology) using the same procedures described above.

Real-time PCR. The total RNA was extracted using Trizol reagents (Promega, USA), according to the manufacturer's instructions and quantified by Nano-drop ND-1000 (Nanodrop, USA). Isolated RNA was electrophoresed through $1 \%$ agarose-formaldehyde gels to verify the quality of the RNA. The first strand cDNA was generated by reverse transcription. The reaction system was: $5 \mathrm{X}$ RNA PCR buffer $4 \mu 1$; dNTP
Table II. The sequences of PCR primers (Takara Bio).

\begin{tabular}{lc}
\hline Name & \multicolumn{1}{c}{ Sequence } \\
\hline Akt1 & \\
Forward & 5'-GGCCCAGATCACCATCAC-3' \\
Reverse & 5'-CTATCGTCCAGCGCAGTCCA-3' \\
B-actin & \\
Forward & 5'-GCCGGGACCTGACTGACTA-3' \\
Reverse & 5'-TGCGGATGTCCACGTCACACT-3' \\
\hline
\end{tabular}

mixture $(10 \mathrm{mM}) 2 \mu \mathrm{l}$; RNase inhibitor $0.5 \mu \mathrm{l}$; MV reverse transcriptase $2 \mu \mathrm{l}$; Oligo-dT, adaptor primer $0.5 \mu \mathrm{l}$; total RNA from sample $(\leq 1 \mu \mathrm{g}) 1 \mu \mathrm{l}$; RNase Free $\mathrm{dH}_{2} \mathrm{O}$ up to $20 \mu \mathrm{l}$. After sufficient cDNA was obtained, we performed PCR amplification using a real-time PCR cycler. The sequences of PCR primers (Takara Bio) are listed in Table II.

To determine the expression level of Akt1, we mixed $10 \mu 1$ 2X PCR premix $\left(\mathrm{Mg}^{2+}\right), 0.5 \mu 1$ Primer-1, $0.5 \mu 1$ Primer-2, $1 \mu 1$

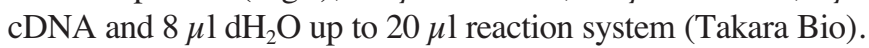
The reactions were incubated in a 96-well optical plate at $94^{\circ} \mathrm{C}$ for $12 \mathrm{~min}$, followed by 40 cycles of $94^{\circ} \mathrm{C}$ for $30 \mathrm{sec}$, $56^{\circ} \mathrm{C}$ for $30 \mathrm{sec}, 72^{\circ} \mathrm{C}$ for $30 \mathrm{sec}, 76^{\circ} \mathrm{C}$ for $2 \mathrm{sec}$ and $72^{\circ} \mathrm{C}$ for $5 \mathrm{~min}$. Melting curve was from $65^{\circ} \mathrm{C}$ to $95^{\circ} \mathrm{C}$, stay for $2 \mathrm{sec}$ and read the plate per $0.2^{\circ} \mathrm{C}$. The expression of Akt1 was examined by normalization of the cycle threshold $(\mathrm{Ct})$ of these genes to that of the control gene (ß-actin), $\Delta \mathrm{Ct}=\mathrm{Ct}_{\mathrm{Akt1}}-\mathrm{Ct}_{\mathrm{B} \text {-actin }}$.

Immunofluorescence. After 24-48 h of transfection, cells were washed 3 times with ice-cold phosphate-buffered saline (PBS), then fixed with $4 \%$ paraformadehyde for $40 \mathrm{~min}$, washed with PBS 3 times, then permeabilized with $1 \%$ Triton X-100 for 5 min and blocked in 1\% BSA for $20 \mathrm{~min}$ at room temperature. Then incubated with primary antibody (1:100 dilution) overnight at $4^{\circ} \mathrm{C}$, then fluorescent secondary antibody $\left(1: 100\right.$ dilution) was added at $37^{\circ} \mathrm{C}$ for $1 \mathrm{~h}$, after washing with PBS, cells were incubated with Hoechst for $20 \mathrm{~min}$ and mounted. The results were observed with a confocal microscopy.

Flow cytometry analysis. Transfected and control cells in the log phase of growth were harvested by trypsinization. Cells were centrifuged for $5 \mathrm{~min}$ at $1000 \mathrm{rpm}$ and washed with PBS, fixed with ethanol. Nuclei of cells were stained with propidium iodide (JingMei Company, Shanghai) for an additional $30 \mathrm{~min}$. Total of 10,000 nuclei were examined in a FACS Calibur flow cytometer (Becton-Dickinson, Heidelberg, Germany) and DNA histograms were analyzed by Modifit software. Cells were stained with Annexin V and propidium iodide was performed as recommended by the manufacturer, and apoptosis was determined by flow cytometry.

Subcutaneous tumor model and gene therapy. Four to sixweek-old female immune-deficient nude mice (BALB/c-nu) were purchased from the animal center of the Cancer Institute of Chinese Academy of Medical Sciences, bred at the facility of laboratory animals, Tianjin University, and housed in 


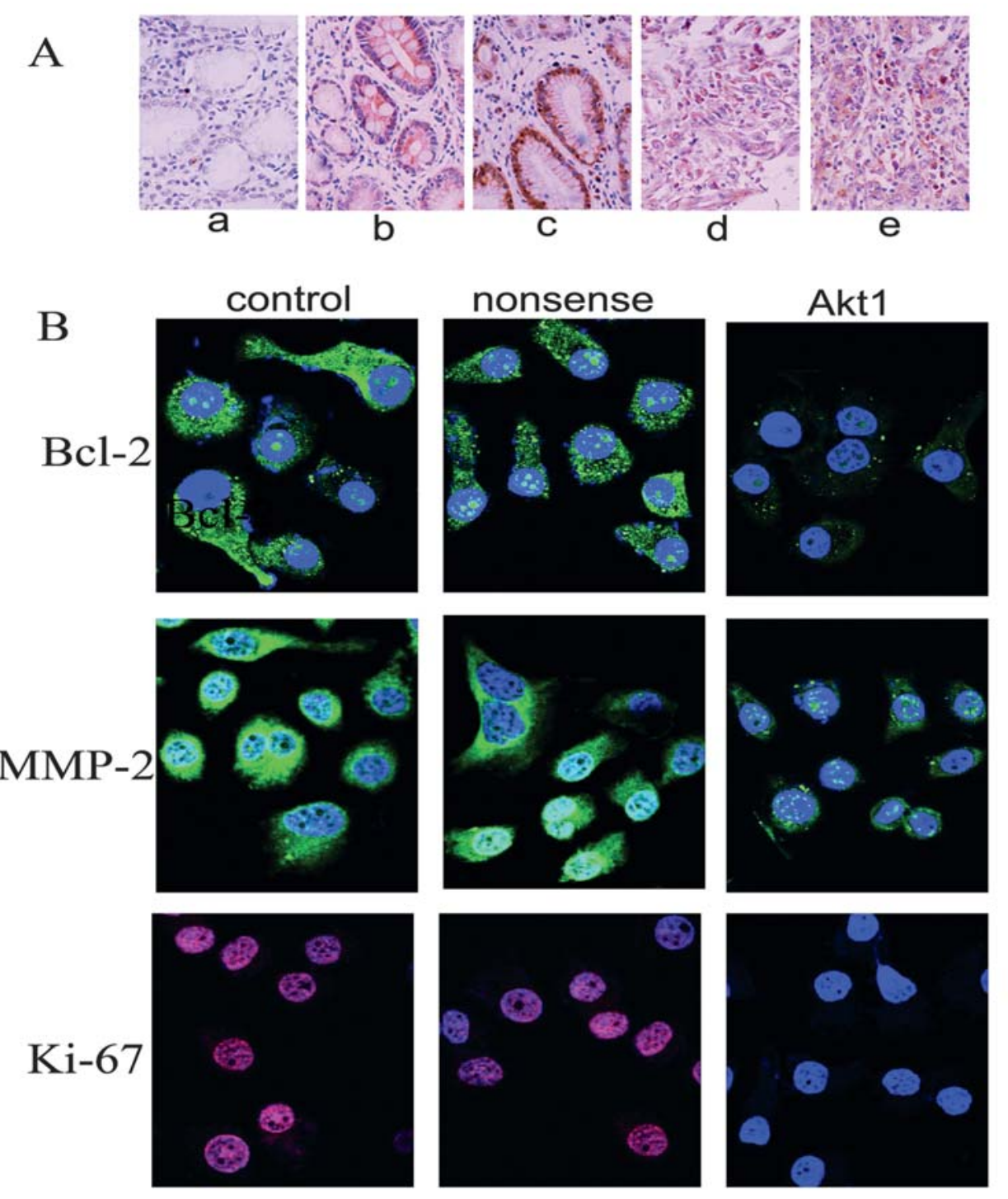

Figure 1. A tissue microarray consisting of biopsies from 45 gastric adenocarcinomas to analyse Akt1 protein expression was constructed (A). The results indicated that Akt1 expression in gastric cancer tissue significantly increased compare to normal tissue and adjacent non-cancer tissue (P<0.05), the difference was not significant $(\mathrm{P}>0.05)$ in well-differentiated, moderately differentiated or poorly differentiated gastric adenocarcinoma, but between well-differentiated and poorly differentiated gastric adenocarcinoma, the difference was significant $(\mathrm{P}<0.05)$. (a) Normal gastric mucosa, (b) adjacent non-cancer tissue, (c) welldifferentiated gastric adenocarcinoma, (d) moderately-differentiated gastric adenocarcinoma, (e) poor-differentiated gastric adenocarcinoma (x200). (B) The results of immunofluorescense indicate that supression of Akt1 expression by siRNA-Akt1 in SGC7901 cells induces down-regulation of Bcl-2, Ki-67 and MMP-2, however, in control and siRNA-nonsense groups, the expression of Bcl-2, Ki67 and MMP-2 present strong, positive immunoreactivity.

microisolator individually ventilated cages with water and food. All experimental procedures were carried out according to the regulations and internal biosafety and bioethics guidelines of Tianjin Medical University and the Tianjin Municipal Science and Technology Commission.

Five mice were injected subcutaneously with $5 \times 10^{7} / \mathrm{ml}$ of SGC7901 cells, in a volume of $50 \mu 1$ of DMEM (serum-free) pre-mixed. Mice were monitored daily. When the tumor size reached approximately $10 \mathrm{~mm}$ in length, the tumors were surgically removed, cut into pieces of $1-2 \mathrm{~mm}^{3}$ and re-seeded in other 24 mice individually. When the tumor size reached approximately $5 \mathrm{~mm}$ in length, the mice were randomly grouped as control, siRNA-nonsense, and siRNA-Akt1; $150 \mu 1$ siRNA and $60 \mu 1$ oligofectamine mixed. In siRNA-nonsense and siRNA-Akt1 groups, $25 \mu \mathrm{l}$ of mixture were injected into subcutaneous tumors of each nude mouse in a multi-site injection manner. Mice in control group received $25 \mu 1$ of PBS only. Another administration was conducted every four days in the same manner until the fourth week, the tumor volume was measured with slider caliper, using the formula: volume $=$ length $\mathrm{x}$ width ${ }^{2} / 2$.

Immunohistochemistry. After 28 days, mice were sacrificed and samples were fixed with $10 \%$ formalin, paraffinembedded tissue sections were used for examination of Akt1, proliferating cell nuclear antigen (PCNA), matrix metalloproteinase-2 (MMP2) and Bcl-2 expression. Sections were dewaxed, treated with $3 \% \mathrm{H}_{2} \mathrm{O}_{2}$ for $7 \mathrm{~min}$ and incubated with primary antibody $(1: 100)$ overnight at $4^{\circ} \mathrm{C}$. Biotinylated secondary antibody $(1: 100)$ was added at $37^{\circ} \mathrm{C}$ for $1 \mathrm{~h}$, followed by the incubation with $\mathrm{ABC}$-peroxidase for an additional $1 \mathrm{~h}$. After washing with PBS, the sections were 


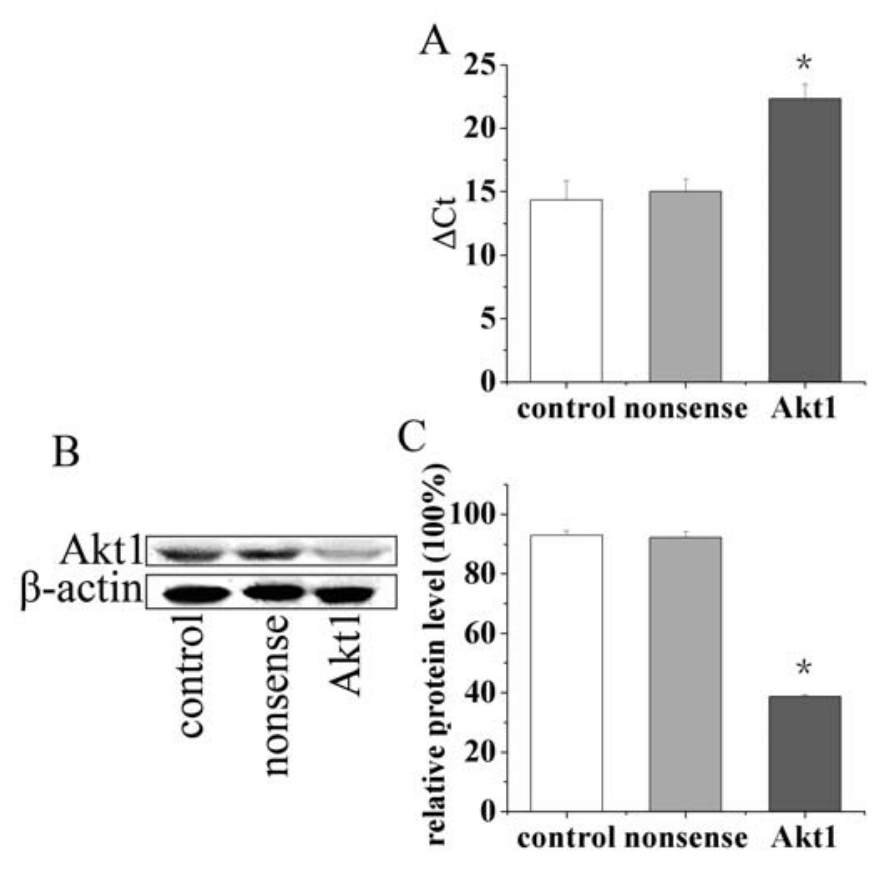

Figure 2. Supression of Akt1 expression by siRNA-Akt1 in SGC7901 cells. (A) Real-time PCR of SGC7901 cells treated with siRNA-Akt1 and siRNAnonsense. (B and C) Western blot analysis of Akt1 expression in SGC7901 cells transfected with siRNA-nonsense, siRNA-Akt1 and in the control group.

incubated with DAB (3,3' diaminobenzidine, $30 \mathrm{mg}$ dissolved in $100 \mathrm{ml}$ Tris-buffer containing $0.03 \% \mathrm{H}_{2} \mathrm{O}_{2}$ ) for $5 \mathrm{~min}$, rinsed in water and counterstained with hematoxylin.
Detection of apoptosis. Apoptosis was detected by TUNEL staining. Briefly, sections were dewaxed, incubated with blocking solution $\left(0.3 \% \mathrm{H}_{2} \mathrm{O}_{2}\right.$ in double diluted water) for 30 min, and permeabilized with $0.1 \%$ Triton X-100 in PBS for another $2 \mathrm{~min}$ on ice. Apoptosis was detected using an in situ cell death kit (Boehringer Mannheim, Germany). Positive cells were visualized by confocal microscopy. The reaction mixture was incubated without enzyme in a control section to detect nonspecific staining.

Statistical analysis. A statistical package SPSS11.5 was used for statistical analysis. One-way analysis of variance (ANOVA) and $\chi^{2}$ test was used to analyze the significance between groups. Statistical significance was determined at $\mathrm{P}<0.05$ level.

\section{Results}

Tissue microarray. We constructed a tissue microarray consisting of biopsies from 45 gastric adenocarcinoma and the gastric mucosa surrounding carcinomas, and 10 samples of normal gastric tissues. We analyzed Akt1 protein expression. The results indicated that in normal gastric mucosa, adjacent non-cancer tissue and gastric adenocarcinoma, the positive rate of Akt1 was 30.00, 66.72 and $71.11 \%$, respectively, and the difference was significant $(\mathrm{P}<0.05)$; in well-differentiated, moderately differentiated and poorly differentiated gastric adenocarcinoma, the positive rate of Akt1 was 50,60 and $84.4 \%$, respectively, and the difference was not significant $(\mathrm{P}>0.05)$, but between well-differentiated and poorly differentiated gastric adenocarcinoma, the difference was significant $(\mathrm{P}<0.05)($ Fig. 1A).
A control

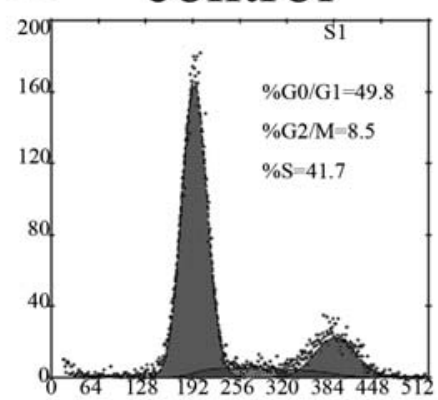

$\mathrm{B}$
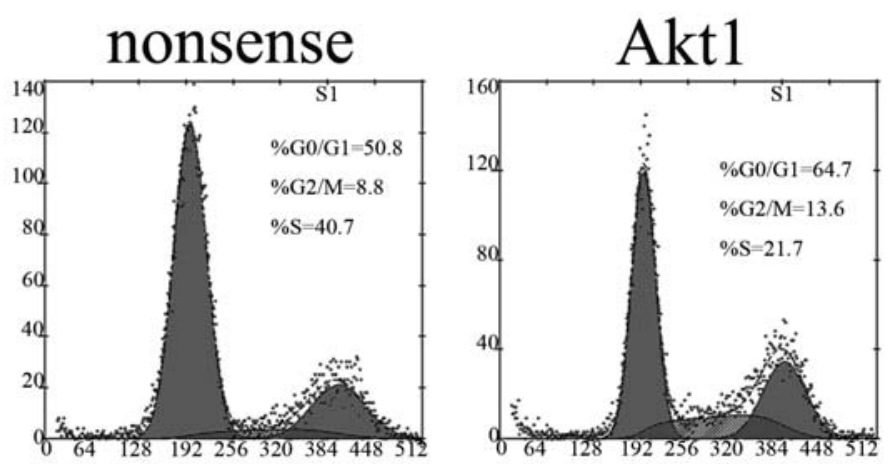

$\mathrm{C}$

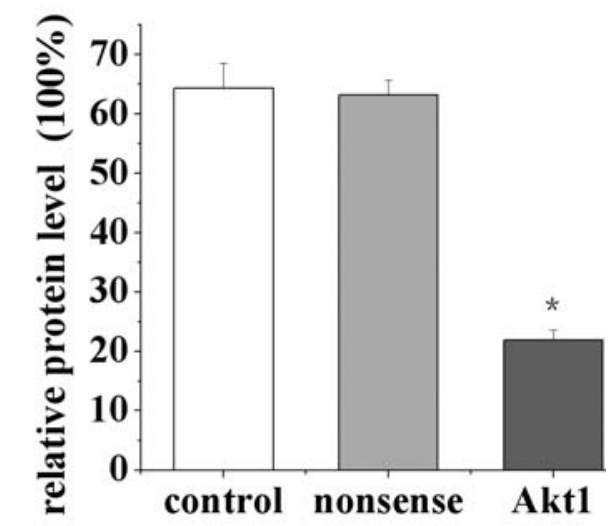

Figure 3. Suppression of Akt1 expression by siRNA-Akt1 in SGC7901 cells induces G0/G1 arrest and inhibits cell growth (A). Cell cycle distrbution of SGC7901 cells after transfection detected with FCM. Transfected and control cells were harvested by trypsinization, washed and fixed overnight, nuclei of cells were stained with propidium iodide, a total of 10,000 nuclei was examined. The expression of cyclin-D1 after transfection with siRNA (B). 


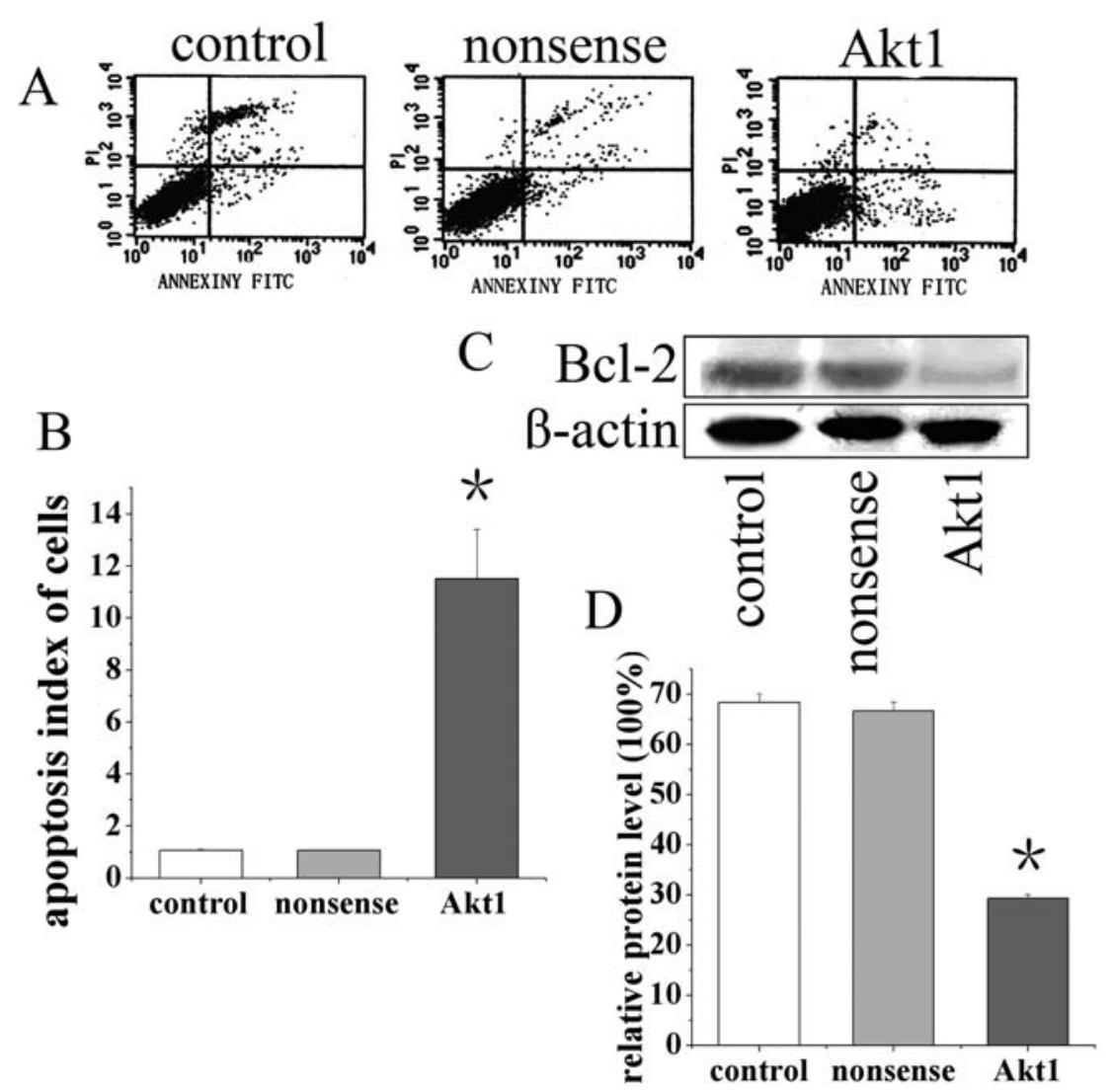

Figure 4. Apoptosis of SGC7901 cells transfected with siRNA-nonsense and siRNA-Akt1 evaluated by Annexin V staining detected with FCM (A and B); the expression of Bcl-2 after transfection with siRNA (C and D).

siRNA-induced gene silencing in SGC7901 cells. Real-time PCR showed that transfection of siRNA-nonsense had little effect on Akt1 expression. However, Akt1 expression was dramatically down-regulated in SGC7901 cells transfected with siRNA-Akt1 ( $\mathrm{P}<0.05)$ (Fig. 2A). Meanwhile, Western blot analysis demonstrated similar down-regulation of Akt1 expression consistent with results from real-time PCR (Fig. $2 \mathrm{~B}$ and $\mathrm{C}$ ). These results suggest that siRNA-Akt1 can potently and specifically inhibit the Akt1 expression in SGC7901 cells.

Immunofluorescence. The expression of Bcl-2, Ki-67 and MMP2 was examined to determine the role of Akt1 in apoptosis, proliferation and invasion in SGC7901 cells. The results indicated the strong, positive immunoreactivity of Bcl-2, Ki-67 and MMP2 in control groups and siRNAnonsense groups. However, the expression of Bcl-2, Ki-67 and MMP2 was down-regulated in the Akt1-siRNA groups (Fig. 1B).

Effect of the Akt1 knock-down on SGC7901 cell proliferation. The cell cycle distribution of control and transfected cells was analyzed by flow cytometry. As shown in Fig. 3A, the G2/M phase fraction of parental SGC7901 cells and cells transfected with siRNA-nonsense and siRNA-Akt1 was 8.5, 8.8 and $13.6 \%$, respectively. The $\mathrm{S}$ phase fraction in parental SGC7901 cells and cells transfected with siRNA-nonsense and siRNA-Akt1 were $41.7,40.4$ and $21.7 \%$, respectively, and decreased significantly in siRNA-Akt1 transfected cells. The
G0/G1 phase fraction in parental SGC7901 cells and in cells transfected with siRNA-nonsense and siRNA-Akt1 were $49.8,50.8$ and $64.7 \%$, respectively. These results suggest that siRNA-Akt1 approach can induce the arrest of cells at G0/G1 phases, delay the progression of cell cycle and inhibit the cell proliferation, and the expression of cyclin-D1 decreased significantly in cells transfected with siRNA-Akt1 (Fig. 3B and C). As shown in Fig. 4A and B, apoptosis of SGC7901 cells treated with siRNA-Akt1 increased significantly compared with siRNA-nonsense and control groups $(\mathrm{P}<0.05)$, and the expression of $\mathrm{Bcl}-2$ decreased in cells treated with siRNA-Akt1 (Fig. 4C and D), suggesting that down-regulation of Akt1 may be involved in the regulation of cell apoptosis.

Cell invasion assessed by MMP-2 and MMP-9. To further evaluate the anti-invasive activity of SGC7901 cells by siRNA-Akt1 approach, we assessed the inhibitory effect on cell invasion through detecting the expression of MMP-2 and MMP-9. Western blot analysis showed that the expression of MMP-2 (Fig. 5A and B) and MMP-9 (Fig. 5C and D) decreased in cells treated with siRNA-Akt1 $(\mathrm{P}<0.05)$. The result suggests that the knock-down of human Akt1 expression by siRNA approach can significantly reduce gastric cancer cell invasion.

Anti-tumor effect of the Akt1 knock-down in SGC7901 gastric cancer xenograft model. Our in vitro experiments demonstrated that siRNA-Akt1 approach can efficiently inhibit cell 

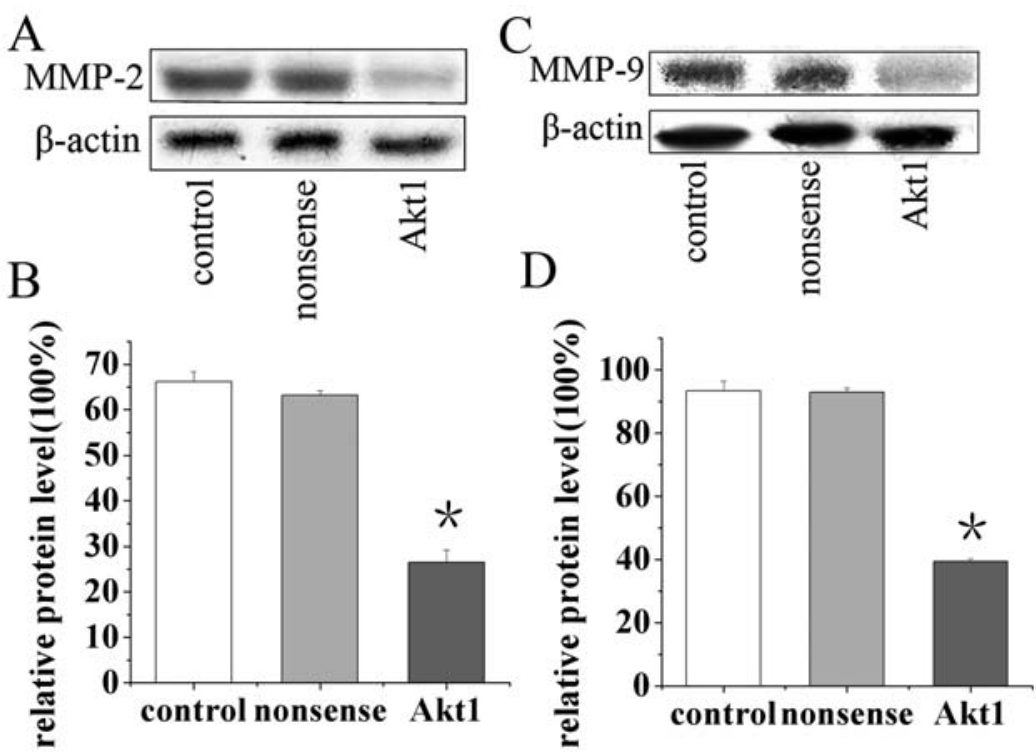

Figure 5. Cell invasive capability of SGC7901 cells. The expression of MMP-2 (A and B) and MMP-9 (C and D) after transfection with siRNA.

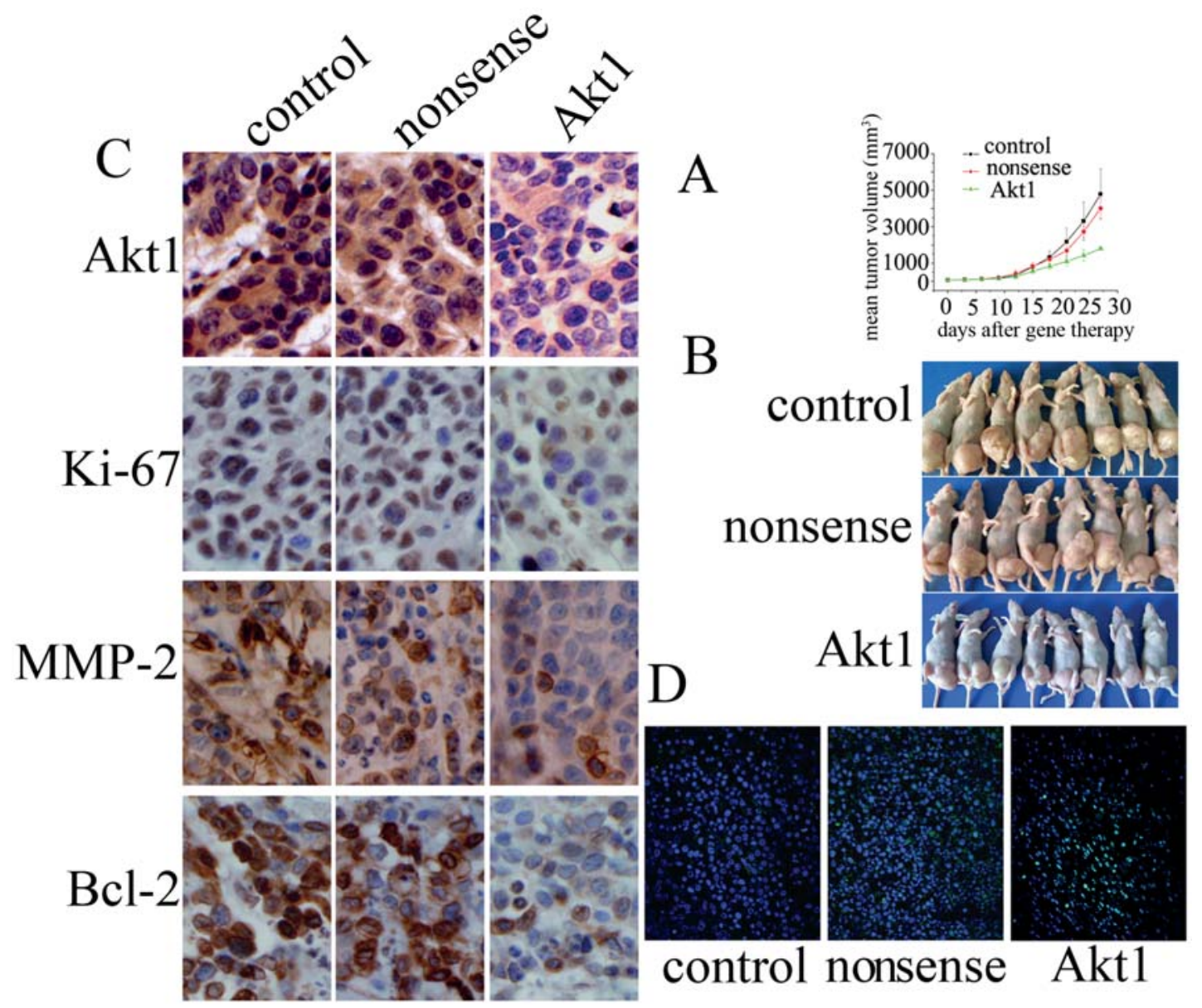

Figure 6. Compared to the control and siRNA-nonsense groups, tumor growth in nude mice in the group of siRNA-Akt1 was inhibited (A and B); compared to the control and siRNA-nonsense groups, Akt1, MMP2, Bcl-2 and Ki-67 were down-regulated (C); apoptotic cells were obvious by TUNEL staining (D).

proliferation, induce the $\mathrm{G} 0 / \mathrm{G} 1$ cell cycle arrest, cell apoptosis and prevent the invasion of SGC7901 cells. Therefore, we further investigated the anti-tumor effect of such approaches in in vivo using SGC7901 gastric cancer xenograft model and oligofectamine-mediated gene therapy as indicated in Materials and methods. Tumors were established in the right leg of 24 mice by SGC7901 xenografts, after reaching approximately $5 \mathrm{~mm}$ in length, and each mouse was challenged by in situ injection of PBS as control $(\mathrm{n}=8)$ or oligofectamine-mediated gene therapy for siRNA-nonsense $(\mathrm{n}=8)$, siRNA-Akt1 $(\mathrm{n}=8)$, respectively. The mean tumor volume of each group at the time of gene therapy was 
$64.80 \pm 15.00 \mathrm{~mm}^{3}, 64.65 \pm 15.08 \mathrm{~mm}^{3}, 63.65 \pm 13.22 \mathrm{~mm}^{3}$, respectively. No statistically significant difference was noted among the groups $(\mathrm{P}=0.985)$. The mice were monitored every three days for 4 weeks, and the tumor volumes were measured and compared. The mean volumes of tumors were $4789.563 \pm 1367.747 \mathrm{~mm}^{3}, 4003.975 \pm 544.457 \mathrm{~mm}^{3}$ and $1797.350 \pm 342.161 \mathrm{~mm}^{3}$ after treatment with PBS oliogofectamine-mediated gene therapy for control, siRNAnonsense and siRNA-Akt1, respectively. The Akt1 knockdown resulted in statistically significant reduction in size of the tumor compared to control and siRNA-nonsense group (Fig. 6A and B).

After mice were observed for 28 days, the tumors were removed and paraffin-embedded section were prepared for immunohistochemical examination using anti-Akt1, MMP2, Bcl-2 and Ki-67 antibodies. Representative sections from mice treated with PBS or oligofectamine-mediated gene therapy for siRNA-Akt1, siRNA-nonsense are shown in Fig. 6A. In control and siRNA-nonsense treated groups, strongly positive immunoreactivity of Akt1, MMP2, Bcl-2 and PCNA were observed (Fig. 6C). TUNEL staining showed that there were nearly no apoptotic cells found in PBS and siRNAnonsense treated groups. However, apoptosis was prominently increased in siRNA-Akt1-treated group (Fig. 6D).

\section{Discussion}

Gene therapy targeting Akt1 in gastric cancer therapy. Akt was discovered as a cellular homologue (c-Akt) of the viral oncogene (v-Akt) from the acutely transforming retrovirus Akt8, isolated from a murine T-cell lymphoma (12). At the same time, it was identified as a novel kinase similar in many respects to protein kinase $\mathrm{A}$ (PKA) and protein kinase $\mathrm{C}(\mathrm{PKC})$ and hence is also referred to as protein kinase $\mathrm{B}$ (PKB) (13). Akt gene encodes a $56 \mathrm{kDa}$ of serine/threonine protein kinase. In mammals, there are three isoforms of Akt (Akt1, 2 and 3 , or $\operatorname{PKB} \alpha ; \beta$ and $\gamma$ ), which have a broad tissue distribution. The expression patterns of the three Akt isoforms differ, as do their apparent biological activities. Akt2 appears to be expressed at greater levels in insulin responsive tissues. Consistent with these data, Akt 2 knockout mice develop mild type 2 diabetes, while Akt1 knockout mice are non-diabetic, but small in size (14). Akt3 expression is more limited, occurring in brain, heart, kidney, and in certain poorly differentiated cancers. All three isoforms are composed of a central catalytic domain, a C-terminal hydrophobic domain, and an $\mathrm{N}$-terminal pleckstrin homology domain (PH domain), making it a target for phospholipids produced by PI3 kinase activity. Akt activity is induced by ligand stimulation of growth factor receptors, such as the insulin-like growth factor-I receptor (IGF-IR) and the EGF family of receptors. It appears that Akt/PKB lies in the crossroads of multiple cellular signaling pathways and acts as a transducer of many functions such as regulating cell growth, proliferation, survival, cell motility, anti-apoptosis, metabolism and other activities. Therefore, dysregulation of Akt-mediated signaling pathways may play an important role in tumor development and progression.

Although in vitro or in vivo studies on several types of human cancer have identified the role of activated Akt, its role in the development and malignancy of gastric carcinoma in vivo and in vitro remains unclear. A previous study reported that Akt was expressed in $74 \%$ of the gastric cancers, and this was not associated with any other clinicopathological factors, and their study also indicated that activated Akt expression was highly detected in early-stage pTNM. This observation is compatible with a study that the overexpression and phosphorylation of Akt is an early event during sporadic colon carcinogenesis (15). Akt activation appears to be required for cell growth and proliferation in early-stage human gastric carcinoma. Oki et al reported that the activated Akt was associated with increased resistance to multiple chemotherapeutic agents (5-fluorouracil, adriamycin, mitomycin $\mathrm{C}$ and cisplatinum) in gastric cancer patients (8). Therefore, down-regulation of the Akt activity seems to be a promising target for gastric cancer therapy. A previous study indicated that small interfering RNA (siRNA) directed against the Akt1 can efficiently suppress its expression in human gastric cancer cell lines leading to the induction of arrest at G1 by inhibiting p27 nuclear import (16). Collectively, the increased expression of Akt1 and the key role that it may play in gastric cancer development and progression led to the investigation of targeting Akt1 for anticancer therapies.

Biological changes by silenced Aktl expression. Akt/PKB is elevated in most gastric cancers (17). One of the earliest studies that identified the two human orthologues, Akt1 and Akt2, based on the homology to the viral oncogene v-Akt, showed a 20-fold amplification of the Akt1 locus in gastric adenocarcinoma (18). It has been reported that in gastric cancer AGS cells transfected with Akt1 siRNA, the expression of Akt1 was dramatically decreased, and the down-regulation of Akt1 significantly down-regulated the expression of Bcl-2, and up-regulated the expression of Bax, but did not alter the expression of PTEN in gastric cancer cells. Our results also indicated down-regulation of Akt1 down-regulated the expression of Bcl-2 and increased the apoptosis of tumor cells. Fan et al showed that overexpression of constitutively active Akt protects cells from COX-2 inhibitor SC236induced cell death and up-regulates the expression of several survival proteins. These results indicate that inhibition of the Akt activity contributes to SC236-induced apoptosis in gastric cancer (19). Akt1 siRNA could significantly enhance the sensitivity of AGS cells to vincristine, adriamycin, 5fluorouracil and cisplatin (20). Another study reported that inhibition of Akt1 is sufficient to affect cell migration, invasion, and proliferation. Expression of Akt1 siRNA had a similar effect as p110 $\alpha$ siRNA in the cells (21). Previous studies indicated that deficiency of Akt1 results in impaired adhesion and migration of endothelial cells to various matrix proteins including fibronectin, vitronectin and fibrinogen, and showed that $\mathrm{Akt}^{-/-}$endothelial cells adhere to fibronectin, vitronectin and fibrinogen with lower affinity compared to WT (22). It was also suggested that Akt1 activation can accelerate the early stages of ErbB-2 mediated tumorigenesis through increased cyclin D1 expression and cellular proliferation (23). A recent study discovered that phospho-Akt1 was overexpressed in human gastric cancers and its levels correlated with tumor differentiation and pTNM. Akt1 activation promoted cell survival because the phosphatidyl- 
inositol 3-kinase (PI3K) inhibitor LY294002 inhibited Akt1 phosphorylation and inhibited cell growth, especially in cells with active Akt1. Dominant negative Akt inhibited proliferation of gastric cancer cells and induced G1 cell-cycle arrest whereas constitutively active Akt increased cell proliferation (24). In the present study, we also found that the expression of Akt1 was decreased via siRNA-Akt1, and biological ability of proliferation, apoptosis and invasion of SGC7901 cells were suppressed. Thus, signal transduction pathways downstream of Akt were found to be critical in mediating important cellular functions, including survival, proliferation, migration, and invasion. Therefor, inhibition of overexpressed and/or activated PI3-K/Akt mediated signaling pathways possess great significance in gastric cancer gene therapy.

Use of siRNA gene therapy for gastric cancer. Gene silencing of target mRNA by RNA interference (RNAi) was first discovered in Caenorhabditis elegans as a response to double-stranded RNA (dsRNA), which resulted in sequence specific gene silencing and has dramatically expanded the arsenal of genetic tools that can be used to study signaling pathways in mammalian systems (25). The triggers for RNAi are small double-stranded RNAs of 21-23 nucleotides in length called small interfering RNAs or siRNA; one of the two strands forms a complex with a set of proteins (the RNA induced silencing complex, or RISC), with the RNA serving as a sequence-specific guide element for identification of the target RNA (26). The mechanism of RNAi was reported in two steps. The first step, referred to as the RNAi initiating step, involves binding of the RNA nucleases to a large dsRNA and the activation of a family of RNase III ribonucleases termed Dicer enzymes, which initiates the cleavage of the dsRNA into 22 nt double-stranded duplexes with 2 nt 3'-overhangs and $5^{\prime}$ phosphate termini, termed the small interfering RNA (siRNA). In the second step, the siRNA is utilized by RISC, which uses the siRNA as a template to recognize and cleave RNA targets with similar nucleotide sequences (27-32). The specific mediator of RNAi is the short dsRNA.

Application of RNAi in mammalian cells demonstrated a particular challenge since introduction of exogenous long dsRNA activates an innate immune (IFN) response, which leads to the inhibition of protein translation by the PKR pathway and activation of RNase L (33). However, transfection of target-specific synthetic short dsRNA (21-23 nt in length) into mammalian cells yielded gene silencing capabilities, which allowed for the routine application of siRNA in mammalian cells (34). Current siRNA selection criteria are based on guidelines first published by Elbashir et al (34). These criteria and subsequent revisions were the result of trial-and-error observations of randomly selected siRNA. Briefly, the requirements include: $21 \mathrm{nt}$ sense and antisense strands paired as to have a 2 nt 3'-overhang, target regions starting 50-100 nt downstream of a start codon, 50\% $\mathrm{G} / \mathrm{C}$ content. The guidelines provide a starting point to design siRNA, but provide little specificity to ensure siRNA knockdown efficacy.

The therapeutic application of siRNA, however, is largely dependent on the development of a delivery vehicle that can efficiently deliver the siRNA to target cells. DNA vector- mediated RNAi technology has made it possible to develop therapeutic applications of this technology in mammalian cells (35). Several examples using retroviral (36-39) or adenoviral vector systems (40) to deliver siRNA for stable or transient expression, respectively, have been reported. In the present study, the expression of Akt1 was decreased using siRNAAkt1, sequently, the biology of SGC7901 cells including proliferation, invasion and apoptosis changed. More studies are needed to test silenced efficacy of various target genes of Akt/PKB pathways, which may become a therapeutic target of gastric cancer.

\section{Acknowledgements}

This work was supported by Tianjin Municipal Natural Science Commission, and by the Natural Science Foundation of Tianjin, Grant No. 07JCZDJC07700 and 09JCZDJC17600, and Program for New Century Excellent Talents in University (NCET-07-0615). We would like to thank Dr Daiming Fan for kindly providing the SGC7901 gastric cancer cells and the members of Tianjin Laboratory of Neuro-oncology, Tianjin Neurological Institute for their technical assistance.

\section{References}

1. Jemal A, Thomas A, Murray T and Thun M: Cancer statistics 2002. CA Cancer J Clin 52: 23-47, 2002.

2. Greenlee RT, Hill-Harmon MB, Murray T and Thun M: Cancer statistics 2001. CA Cancer J Clin 51: 15-36, 2001.

3. Roder D: The Epidemiology of gastric cancer. Gastric Cancer 5 (Suppl 1): 5-11, 2002.

4. Ilson DH: Adjuvant therapy for noncolorectal cancers. Curr Opin Oncol 13: 287-290, 2001.

5. Somanath PR, Razorenova OV, Chen J and Byzova TV: Akt1 in endothelial cell and angiogenesis. Cell Cycle 5: 512-518, 2006.

6. Chen J, Somanath PR, Razorenova O, Chen WS, Hay N, Bornstein P and Byzova TV: Akt1 regulates pathological angiogenesis, vascular maturation and permeability in vivo. Nat Med 11: 1188-1196, 2005

7. Ang KL, Shi DL, Keong WW and Epstein RJ: Upregulated Akt signaling adjacent to gastric cancers: implications for screening and chemoprevention. Cancer Lett 225: 53-59, 2005.

8. Oki E, Baba H, Tokunaga E, et al: Akt phosphorylation associates with LOH of PTEN and leads to chemoresistance for gastric cancer. Int J Cancer 117: 376-380, 2005.

9. Itoh N, Semba S, Ito M, Takeda H, Kawata $S$ and Yamakawa M: Phosphorylation of Akt/PKB is required for suppression of cancer cell apoptosis and tumor progression in human colorectal carcinoma. Cancer 94: 3127-3134, 2002.

10. Ruggeri BA, Huang L, Wood M, Cheng JQ and Testa JR: Amplification and overexpression of the Akt 2 oncogene in a subset of human pancreatic ductal adenocarcinomas. Mol Carcinog 32: 81-86, 1998.

11. Elbashir SM, Harborth J, Weber K and Tuschl T: Analysis of gene function in somatic mammalian cells using small interfering RNAs. Methods 26: 199-221, 2002.

12. Staal SP, Hartley JW and Rowe WP: Isolation of transforming murine leukemia viruses from mice with a high incidence of spontaneous lymphoma. Proc Natl Acad Sci USA 74: 3065-3067, 1977.

13. Coffer PJ and Woodgett JR: Molecular cloning and characterisation of a novel putative protein - serine kinase related to the cAMP-dependent and protein kinase $\mathrm{C}$ families. Eur J Biochem 201: 475-481, 1991.

14. Chen WS, Xu PZ, Gottlob K, et al: Growth retardation and increased apoptosis in mice with homozygous disruption of the Akt1 gene. Genes Dev 15: 2203-2208, 2001.

15. Roy HK, Olusola BF, Clemens DL, Karolski WJ, Ratashak A, Lynch HT and Smyrk TC: Akt proto-oncogene overexpression is an early event during sporadic colon carcinogenesis. Carcinogenesis 23: 201-205, 2002. 
16. Liang J, Zubovitz J, Petrocelli T, et al: PKB/Akt phosphorylates p27, impairs nuclear import of p27 and opposes p27-mediated G1 arrest. Nat Med 8: 1153-1160, 2002.

17. Izuishi K, Kato K, Ogura T, Kinoshita T and Esumi $\mathrm{H}$ : Remarkable tolerance of tumor cells to nutrient deprivation: possible new biochemical target for cancer therapy. Cancer Res 60: 6201-6207, 2000

18. Staal SP: Molecular cloning of the Akt oncogene and its human homologues Akt1 and Akt2: amplification of Akt1 in a primary human gastric adenocacinoma. Proc Natl Acad Sci USA 84: 5034-5037, 1987.

19. Fan XM, Jiang $\mathrm{XH}, \mathrm{Gu} \mathrm{Q}$, et al: Inhibition of $\mathrm{Akt} / \mathrm{PKB}$ by a COX-2 inhibitor induces apoptosis in gastric cancer cells. Digestion 73: 75-83, 2006.

20. Han Z, Hong L, Wu K, et al: Reversal of multidrug resistance of gastric cancer cells by downregulation of Akt1 with Akt1 siRNA. Clin Cancer Res 25: 601-606, 2006.

21. Meng Q, Xia C, Fang J, Rojanasakul Y and Jiang BH: Role of $\mathrm{PI} 3 \mathrm{~K}$ and Akt specific isoforms in ovarian cancer cell migration invasion and proliferation through the p70S6K1 pathway. Cell Signal 18: 2262-2271, 2006.

22. Somanath PR, Kandel ES, Hay N and Byzova TV: Akt1 signaling regulates integrin activation, matrix recognition and fibronectin assembly. J Biol Chem 282: 22964-22976, 2007.

23. Hutchinson JN, Jin J, Cardiff RD, Woodgett JR and Muller WJ: Activation of Akt-1 (PKB-alpha) can accelerate ErbB-2-mediated mammary tumorigenesis but suppresses tumor invasion. Cancer Res 64: 3171-3178, 2004.

24. Han Z, Wu K, Shen H, et al: Akt1/protein kinase B alpha is involved in gastric cancer progression and cell proliferation. Dig Dis Sci 53: 1801-1810, 2008

25. Fire A, Xu S, Montgomery MK, Kostas SA, Driver SE and Mello CC: Potent and specific genetic interference by doublestranded RNA in Caenorhabditis elegans. Nature 391: 806-811, 1998.

26. Sijen T, Fleenor J, Simmer F, et al: On the role of RNA amplification in dsRNA-triggered gene silencing. Cell 107: 465-476, 2001

27. Agrawal N, Dasaradhi PV, Mohmmed A, Malhotra P, Bhatnagar RK and: Mukherjee SK: RNA Interference: biology, mechanism, and applications. Microbiol Mol Biol Rev 67: $657-685,2003$
28. Zamore PD, Tuschl T, Sharp PA and Bartel DP: RNAi: doublestranded RNA directs the ATP-dependent cleavage of mRNA at 21 to 23 nucleotide intervals. Cell 101: 25-33, 2000.

29. Hammond SM, Bernstein E, Beach D and Hannon GJ: An RNA-directed nuclease mediates post-transcriptional gene silencing in Drosophila cells. Nature 404: 293-296, 2000.

30. Nykanen A, Haley B and Zamore PD: ATP requirements and small interfering RNA structure in the RNA interference pathway. Cell 107: 309-321, 2001.

31. Elbashir SM, Lendeckel W and Tuschl T: RNA interference is mediated by 21 - and 22-nucleotide RNAs. Genes Dev 15: 188-200, 2001

32. Elbashir SM, Martinez J, Patkaniowska A, Lendeckel W and Tuschl T: Functional anatomy of siRNAs for mediating efficient RNAi in Drosophila melanogaster embryo lysate. EMBO J 20: 6877-6888, 2001.

33. Bass BL: RNA interference: the short answer. Nature 411: 428-429, 2001

34. Elbashir SM, Harborth J, Lendeckel W, Yalcin A, Weber K and Tuschl T: Duplexes of 21-nucleotide RNAs mediate RNA interference in cultured mammalian cells. Nature 411: 494-498, 2001.

35. McCaffrey AP, Meuse L, Pham TT, Conklin DS, Hannon GJ and Kay MA: RNA interference in adult mice. Nature 418: 38-39, 2002.

36. Barton GM and Medzhitov R: Retroviral delivery of small interfering RNA into primary cells. Proc Natl Acad Sci USA 99: 14943-14945, 2002.

37. Paddison PJ and Hannon GJ: RNA interference: the new somatic cell genetics? Cancer Cell 2: 17-23, 2002.

38. Rubinson DA, Dillon CP, Kwiatkowski AV, et al: A lentivirusbased system to functionally silence genes in primary mammalian cells, stem cells and transgenic mice by RNA interference. Nat Genet 33: 401-406, 2003.

39. Tiscornia G, Singer O, Ikawa M and Verma IM: A general method for gene knockdown in mice by using lentiviral vectors expressing small interfering RNA. Proc Natl Acad Sci USA 100: 1844-1848, 2003

40. Xia H, Mao Q, Paulson HL and Davidson BL: siRNA-mediated gene silencing in vitro and in vivo. Nat Biotechnol 20: 1006-1010, 2002 . 